\title{
Cost-Effectiveness of Entecavir versus Lamivudine for the Suppression of Viral Replication in Chronic Hepatitis B Patients in Brazil
}

Anna Maria N. Costa ${ }^{1}$, Gilbert L.'Italien ${ }^{2}$, Marcelo Eidi Nita ${ }^{1}$ and Evaldo Stanislau A. Araujo ${ }^{3}$

${ }^{1}$ Global Development and Medical Affairs da Bristol-Myers Squibb Company, São Paulo; ${ }^{2}$ Global Epidemiology and Outcome Research, Bristol-Myers Squibb, Wallingford, CT, USA; ${ }^{3}$ Infectious Diseases Division of Clinical Hospital of Medical School of São paulo University; São Paulo, SP, Brazil

\begin{abstract}
Hepatitis B virus infection is an important public-health issue. Chronic patients have a higher risk of death due to complications, which increases health-care expenses in. Cost-effectiveness analysis of entecavir (ETV) versus lamivudine (LVD) for treatment of chronic hepatitis B, in $e$ antigen (AgHBe)-positive and negative patients, based on two phase 3, controlled and randomized studies. A decision analysis model was developed, using the following endpoints: cost per patient with undetectable viral load and cost per quality life year (QALY) gained. Risks for complications (compensated or decompensated cirrhosis and hepatocellular carcinoma) were based on the cohort study REVEAL, published in 2006. The REVEAL parameters were applied to the results of the viral load levels obtained from the clinical assay data. The complication costs were based on a study of the disease cost conducted in Brazil, in 2005. The cost data were obtained predominantly from Sistema Único de Saúde [SUS - Brazilian public health system] payment tables and drug price lists. The utility data were obtained from literature and life expectancy information was based on IBGE data. The analysis perspective was that of SUS. A discount rate of $3 \%$ per year was used. For the horizon of time of $\mathbf{1 0}$ years, the ETV had an incremental cost of approximately two million Brazilian Reais (R\$) compared to LVD. Reducing the number of complications, ETV treatment reduced costs by around 3 million, reducing final costs by 1 million, for AgHBe-positive patients. ETV also reduced the incremental cost per QALY gained. ETV was found to be the most cost-effective alternative for AgHBe-positive and negative patients. Key-Words: Chronic hepatitis B, cost, treatment.
\end{abstract}

Hepatitis B virus (HBV) infection is an important public health issue, due to its potential to evolve to chronic forms of the disease (CHB), characterized by persistence of the hepatitis $B$ virus surface antigen (AgHBs); the chronic form of the disease has important economic impacts for society. In addition to AgHBs, other antigens are found in the blood, such as the $e$ antigen (AgHBe). Independent of whether infections are positive for this antigen, hepatic disease continues to progress, affecting approximately 350 million people worldwide. In Brazil, at least $15 \%$ of the population have already been in contact with hepatitis B virus and 1\% present chronic disease. Subjects with chronic infection have a higher risk of death for disease complications, such as hepatic cirrhosis and hepatocellular carcinoma (HCC), which also contribute to increased costs due to morbidity [1-3].

CHB treatment has as a primary objective prevention of cirrhosis or HCC. According to the latest U.S. algorithm for the treatment of this disease, prevention can be attained through viral DNA suppression to minimal values during the longest time possible [4]. At the moment, there are two drugs available for CHB treatment in the Programa Nacional de Hepatites Virais [National Program of Viral Hepatitis], of the Ministry of Health: interferon-alpha and lamivudine (LVD). LVD has drawbacks, including a high rate of occurrence of

Received on 11 April 2008; revised 25 September 2008.

Address for correspondence: Dr. Anna Maria N. Costa, MD, PhD. Email: anna-maria.costa@bms.com. Telephone : 113882 2374. BristolMyers Squib Farmacêuticas S/A. Rua Carlos Gomes, 924, Santo Amaro - SP. Zip code:: 04743-903.

The Brazilian Journal of Infectious Diseases

2008;12(5):368-373. (C) 2008 by The Brazilian Journal of Infectious Diseases and Contexto Publishing. All rights reserved. mutant virus, which has been generating discussions and preoccupations by medical societies. The incidence of CHB complications and the limitation of therapies available for the treatment of the CHB disease that reduce and control the viral load are factors contributing to increases inhealth expenses in the Sistema Único de Saúde (SUS), due to CHB.

Entecavir (ETV) is the newest oral antiviral agent approved for the treatment of this disease. It is a carbocyclic analogue of 2'-deoxyguanosine, with accentuated in vitro and in vivo activity against viral DNA polymerase, inhibiting viral replication [5]. It has been found to have greater efficacy than LVD, with fewer long-term complications.

In several studies, ETV presented favorable profiles of efficacy, safety and resistance [6-8]. In a recent metanalysis [6], which evaluated AgHBe-positive and negative patients, an efficacy comparison was made for ETV, LVD and adefovir, after 48-52 weeks of treatment. In HBeAg-positive patients, ETV more effectively reduced viral DNA levels than did LVD or adefovir $(\mathrm{p}<0.0001)$. In two randomized, Phase III, multicenter, clinical assays $[7,8]$, the efficacy and safety of ETV were compared to those of LVD, after 52 weeks of treatment of patients with $\mathrm{CHB}$, who were HBeAg-positive or negative. In AgHBe-positive patients, the reduction in viral DNA levels to undetectable values was greater in the ETV group, than with LVD $(\mathrm{p}<0.0001)$. In AgHBe-negative patients, the proportion of patients reaching undetectable levels of viral DNA was higher in the ETV group, in comparison with LVD $(\mathrm{p}<0.001)$. In both studies, no resistance to ETV was observed after 48 weeks of treatment, and there was no significant difference in the toxicity profiles of these drugs.

Given the existing scientific evidence of the superiority in efficacy of ETV compared to LVD for chronic hepatitis B 
treatment, we made a cost-effectiveness analysis of these two therapies, using Brazilian Sistema Único de Saúde (SUS) data.

\section{Material and Methods}

The cost-effectiveness analysis of ETV was evaluated in two ways:

(a) comparing the drug costs with the estimated costs associated with disease complications, during a clinical study that involved treatment to attain undetectable viral loads;

(b) comparing drug costs with the estimated costs associated with disease complications, measured in life-years and quality life-years.

The endpoints studied in the economic analysis were: cost per patient to reach undetectable viral load and cost per additional quality-adjusted life year (QALY).

The cost-effectiveness analysis was based on a decision tree model. A hypothetical cohort of 1,000 patients initially was treated with ETV $(n=500)$ or LVD $(n=500)$. Throughout the simulation, these subjects could develop resistance to treatment or could return to the original viral load levels after the end of the treatment. The model was constituted of five stages: Chronic Hepatitis B (CHB), compensated cirrhosis (CC), decompensated cirrhosis (DC), hepatocellular carcinoma (HCC) and death. The viral load values were updated yearly to incorporate efficacy results of the first year of treatment and the impact on subsequently developing resistance and returning to the viral load levels after the end of therapy. Disease complications were projected along 10 years, for the two treatment arms, based on the R.E.V.E.A.L study. Some model parameters were also based on this study: patients with CHB could progress directly to HCC; while to progress to DC, they had to first pass through the CC stage. Furthermore, patients who developed resistance with the use of LVD could go on adefovir, as a rescue therapy. The discount rate was $3 \%$ per year and the horizon of time was 10 years.

\section{Cost and Efficacy Data}

Drugs

The LVD price was based on Decree 2.577/2006, which determines the cost to the states. It is supplied by the Federal Government through the CMDE (Componente de Medicamentos de Dispensação Excepcional), as per Decree MS/GM N.2.577, dated October 27, 2006, which established the value passed on to the states at $\mathrm{R} \$ 0.69$ per tablet.
The price considered for ETV was R \$ 15.16. The amount passed on to the states was $80 \%$ of this value. This percentage was determined based on rules established by the Ministry of Health in the management of the PNMDCE (Programa Nacional de Medicamentos de Dispensação em Caráter Excepcional), as foreseen in article 19 of Decree MS/GM 698/ 2006, which determines the system of co-financing between the federal and state governments, as well as Decree MS/GM 2577/2006 and its annexes (descriptive and drug tables and pass-on values). Assuming the federal charge of $80 \%$, it is the responsibility of the states to pay the difference between this value and the effective purchase value. Therefore, the pass-on value of the federal government for ETV was R 12.13 .

\section{Disease Complications}

Number of Cases of CC, DC and HCC Used in the Model

The results of the R.E.V.E.A.L. study were used for projections of the number of complications along time, based on the viral load, in which 3,653 subjects infected by HBV and who were not being treated were invited to take part in the study from 1991-1992 and observed during 11.4 years $[9,10]$. In this study, the association between viral load levels seen in the patients and the risk of development of CC, DC and HCC was examined. During the follow-up period, 365 cases of CC, 39 cases of DC and 164 new cases of HCC were diagnosed. Table 1 presents the percent of CC, DC and HCC cases among the 3,653 patients.

We found a strong association between high viral load levels and the risk to develop hepatic complications, which, in addition to affecting the quality and quantity of the lifeyears of the infected patients, increased health system costs.

\section{Number of Patients at Each Viral Load Level}

According to the R.E.V.E.A.L. findings, high viral load levels are associated with increasing incidence of complications of CHB, such as CC, DC and HCC., Data from two clinical assays were used to compare how the two therapies affect viral load levels (Table 2).

AI463-022 [11]: Phase III clinical assay, 48 weeks in duration, with 715 AgHBe-positive patients, without any previous treatment;

AI463-027 [12]: Phase III clinical assay, 48 weeks in duration, with 648 AgHBe-negative patients, without any previous treatment.

Table 1. Distribution of compensated and decompensated cirrhosis and hepatocellular carcinoma cases (R.E.V.E.A.L. Study).

\begin{tabular}{lccc}
\hline $\begin{array}{l}\text { Viral load } \\
\text { (copies/mL) }\end{array}$ & Compensated cirrhosis (\%) & Decompensated cirrhosis (\%) & Hepatocellular carcinoma (\%) \\
\hline$<300$ & 3.9 & 0.7 & 1.3 \\
$\geq 300-<10^{3}$ & 4.9 & 0.5 & 1.3 \\
$\geq 10^{3}-<10^{4}$ & 8.7 & 0.3 & 3.4 \\
$\geq 10^{4}-<10^{5}$ & 19.5 & 1.4 & 10.6 \\
$\geq 10^{6}$ & 25.6 & 3.0 & 12.6 \\
\hline
\end{tabular}


Table 2. Percent of patients with different viral load levels in the AI463-022 (HBeAg+ patients) and AI463-027 (HBeAg- patients) studies.

\begin{tabular}{|c|c|c|c|c|}
\hline \multirow{2}{*}{$\begin{array}{l}\text { Viral load levels } \\
\text { (copies/mL) }\end{array}$} & \multicolumn{2}{|c|}{ AI463-022 } & \multicolumn{2}{|c|}{ AI463-027 } \\
\hline & $\operatorname{ETV}(\%)$ & LVD (\%) & $\operatorname{ETV}(\%)$ & LVD (\%) \\
\hline$<300$ & 69.1 & 39.8 & 93.3 & 75.6 \\
\hline$\geq 300-<10^{4}$ & 24.7 & 18.2 & 4.1 & 12.5 \\
\hline$\geq 10^{4}-<10^{5}$ & 4.4 & 11.7 & 1.6 & 5.1 \\
\hline$\geq 10^{5}-<10^{6}$ & 0.6 & 9.3 & 0.3 & 2.0 \\
\hline$\geq 10^{6}$ & 1.2 & 21.0 & 0.6 & 4.8 \\
\hline
\end{tabular}

Relative risks for complications, according to viral load levels seen at the $48^{\text {th }}$ week of the clinical assays, to project the number of CC, DC and HCC cases after 10 years of disease and, consequently, estimate the impact on quality of life and costs.

\section{Annual Costs Due to the CHB Complications}

The annual costs per patient with CC, DC and CHC, used in the analysis, were extracted from a local study [13] concerning the cost of CHB in 2005, in Brazil, based on SUS information. The objective of that study was to describe the standard treatment, the use of resources and the direct costs for each stage of CHB in the SUS system, in 2005. Direct costs included: admissions, diagnostic and therapeutic interventions, complementary exams, expenses with drugs and professional fees. A Delphi panel of specialists was developed to obtain information on the standard treatment of this disease in Brazil. Data were collected by 10 specialist physicians, hepatologists and infectologists. Data on costs were obtained predominantly from SUS payment tables and drug price lists. Estimated costs of CC, DC and CHC for SUS are shown in Table 3.

Table 3. Estimated annual cost per patient at each stage of the disease, based on SUS data, in 2005.

\begin{tabular}{lc}
\hline CHB Stage & Cost for SUS (R\$) \\
\hline Compensated cirrhosis & $3,527.90$ \\
Decompensated cirrhosis & $22,022.61$ \\
Hepatocellular carcinoma & $4,764.95$ \\
\hline
\end{tabular}

Source: Castelo A., Pessoa M.G., Barreto T.C.B.B., et al. Estimativas de custo da hepatite B crônica no Sistema Único de Saúde brasileiro em 2005. Rev Assoc Med Bras 2007;53:486-91.

\section{Quality of Life}

The life expectancies for CHB and CC were estimated from 2003 data of the Instituto Brasileiro de Geografia e Estatística [14]. The life expectancies for DC and HCC were based on the method of declining exponential approximation (DEALE) [15], which is based on the inverse of the annual mortality of these complications. The annual mortality considered for DC was $14.4 \%$, while it was $23.3 \%$ for HCC, based on literature data [16,17]. Utility scores were calculated for the different stages of disease, through a visual analogue scale and the standard gamble method. Scores calculated for CHB, CC, DC and HCC were, respectively, 0.68, $0.69,0.35$ and 0.38 [18]. To avoid errors of double counting in calculating the lost life-years for patients with multiple events, some premises were established, based on the R.E.V.E.A.L. study: all patients presenting DC had previous CC; $72 \%$ of the patients with HCC had previous CC; if the patients presented CC and DC or CC and HCC simultaneously, only the life expectancies of the DC and HCC complications were considered; no patient had DC and HCC at the same time.

\section{Results}

Presuming a population of 1,000 patients with CHB, being treated with ETV and LVD during one year, the total cost of drugs was estimated to be, approximately, $\mathrm{R} \$ 2,000,000$ and $\mathrm{R} \$ 120.000$, respectively.

We used information on the risks to develop CC, DC and HCC, at different viral load levels reported in the R.E.V.E.A.L. study, to determine how treatment with ETV and LVD affected the risks for these complications. We estimated that 68 cases of CC, 9 of DC and 42 of HCC would be prevented by treatment with ETV in E antigen-positive and -negative patients. This reduced medical costs for the treatment of these complications by approximately R \$ 3 million. When we included the costs of the drugs, the inclusion of ETV in the treatment of this disease reduced costs by about $\mathrm{R} \$ 1$ million for SUS, considering the population of $\mathrm{E}$ antigen-positive and negative patients.

ETV, in comparison with LVD, resulted in a lower cost per patient reaching undetectable viral load, a lower cost per lifeyear saved and a lower cost per QALY gained, in both HBeAgnegative and HBeAg-positive patients, resulting in reduced costs for public health systems.

Tables 4, 5, 6 and 7 show the main results obtained from this cost-effectiveness analysis of ETV in comparison with LVD, for treating HBeAg-positive and negative patients.

To study the effect of ambiguity on the robustness of our results, we performed a sensitivity analysis, varying the costs of treatment of the different stages of the disease by $10 \%$. We used this parameter because of the variability of costs within the country. The results can be seen in Table 8 .

Sensitivity Analysis

To evaluate whether entecavir was also cost-effective for 
Table 4. Cost of drugs, complications and efficacy values of ETV, LVD, and net benefit, in HBeAg-positive patients.

\begin{tabular}{lccc}
\hline Treatments compared & ETV & LVD & Net benefit \\
\hline Drugs & & & $\mathrm{R} \$ 11.44$ \\
$\quad$ Daily cost / patient & $\mathrm{R} \$ 12.13$ & $\mathrm{R} \$ 0.69$ & 16.8 \\
$\quad$ Days of use in the year & 358.9 & $\mathrm{R} 2.1$ & $\mathrm{R} \$ 2,058,832$ \\
$\quad$ Aggregated yearly cost & $\mathrm{R} 2,178,574$ & $\mathrm{R} \$ 119,740$ & -77 \\
CHB complications & 28 & 66 & -9 \\
$\quad$ Estimated cases of CC & 2 & 7 & -48 \\
Estimated cases of DC & 12 & 36 & $-\mathrm{R} \$ 3,222,174$ \\
Estimated cases of CHC & $\mathrm{R} \$ 2,179,846$ & $\mathrm{R} \$ 5,402,020$ & 29 \\
Total medical costs & & & 147 \\
Endpoints considered & 69.1 & 39.8 & -443 \\
$\quad$ Percent with undetectable viral load (\%)* & 346 & 199 & -397 \\
Patients with undetectable viral load (N) & -224 & -667 & -598 \\
Lost life-years & -201 & &
\end{tabular}

Table 5. Incremental cost-effectiveness ratio, in reais, for the three endpoints considered in HBeAg-positive patients.

\begin{tabular}{ll}
\hline \multicolumn{2}{c}{ Incremental cost-effectiveness ratio (ICER) } \\
\hline Cost / patient with undetectable viral load & $-\mathrm{R} \$ 7,938$ \\
Cost / LYG & $-\mathrm{R} \$ 2,626$ \\
Cost / QALY & $-\mathrm{R} \$ 2,930$ \\
\hline LYG - Life-years gained. QALY - Quality life-years gained.
\end{tabular}

Table 6. Cost of drugs, complications and efficacy values of entecavir (ETV) and lamivudine (LVD) and net benefit, in HBeAgnegative patients.

\begin{tabular}{lccc}
\hline Treatments compared & ETV & LVD & Incremental \\
\hline Drugs & $\mathrm{R} \$ 12.13$ & $\mathrm{R} \$ 0.69$ & $\mathrm{R} \$ 11.44$ \\
$\quad$ Daily cost/patient & 357.7 & 354.5 & 3.2 \\
$\quad$ Days of use in year & $\mathrm{R} \$ 2,170,946$ & $\mathrm{R} \$ 124,060$ & $\mathrm{R} \$ 2,046,886$ \\
$\quad$ Aggregated yearly cost & & & -30 \\
CHB complications & 20 & 50 & -4 \\
$\quad$ Estimated cases of CC & 1 & 26 & -18 \\
Estimated cases of DC & 8 & $\mathrm{R} \$ 4,049,592$ & $-\mathrm{R} \$ 2,527,058$ \\
Estimated cases of CHC & $\mathrm{R} \$ 1,522,534$ & 75.6 & 18 \\
$\quad$ & & 378 & 89 \\
Total medical costs & 93.3 & -479 & -337 \\
$\quad$ Percent with undetectable viral load (\%)* & 467 & -429 & -302 \\
$\quad$ Patients with undetectable viral load (N) & -142 & &
\end{tabular}

Table 7. Incremental cost-effectiveness ratio, in reais, for the three outcomes considered in HBeAg-negative patients.

\begin{tabular}{lc}
\hline \multicolumn{2}{c}{ Incremental cost-effectiveness ratio } \\
\hline Cost / patient with undetectable viral load & $-\mathrm{R} \$ 5,420$ \\
Cost / LYG & $-\mathrm{R} \$ 1,424$ \\
Cost / QALY & $-\mathrm{R} \$ 1,590$ \\
\hline
\end{tabular}

LYG - Life-years gained. QALY - Quality life-years gained. 
Table 8. Incremental Cost-Effectiveness Ratio (ICER), in reais, for the three outcomes considered for HBeAg-positive and negative patients.

\begin{tabular}{|c|c|c|c|c|}
\hline \multirow[t]{2}{*}{ ICER } & \multicolumn{2}{|c|}{ HBeAg positive } & \multicolumn{2}{|c|}{ HBeAg negative } \\
\hline & $-10 \%(R \$)$ & $+10 \%(\mathrm{R} \$)$ & $-10 \%(\mathrm{R} \$)$ & $+10 \%(\mathrm{R} \$)$ \\
\hline Cost/patient with undetectable viral load & $-5,744$ & $-10,142$ & $-2,574$ & $-8,280$ \\
\hline Cost / LYG & $-1,900$ & $-3,356$ & -676 & $-2,176$ \\
\hline Cost / QALY & $-2,120$ & $-3,744$ & -754 & $-2,428$ \\
\hline
\end{tabular}

LYG - Life-years gained. QALY - Quality life-years gained.

efficacy observed for entecavir in the first year would be sustained beyond the trial period without any incremental benefit. In the long-term analysis, we assumed that as long as patients were taking lamivudine, additional patients would develop treatment resistance each year. Assumed cumulative lamivudine viral resistance rates from years 1 to 5 were 14, 38, 49,66 , and $69 \%$, with $69 \%$ beyond 5 years. We assumed that patients developing lamivudine resistance would be treated by adding adefovir to the therapy, based on recent clinical practice in the management of lamivudine-resistance patients, while also assuming that medication efficacy would not worsen. The results are described in Table 9.

\section{Discussion}

ETV is one of the drugs that has been recently approved for the treatment of CHB. Several consistent Phase III studies have shown favorable profiles of efficacy and safety, including, higher efficacy of ETV in comparison with LVD. Two of the factors involved in the superior efficacy of ETV are its capacity to maintain viral load at undetectable levels and minimal rates of resistance for long periods of time. Some cost-effectiveness studies have been published recently, showing that ETV is a cost-effective alternative in patients with CHB [19-21].

At the moment, one of the most widely-used antiviral agents to treat CHB in the SUS system is LVD, which has given higher rates of resistance and less efficient viral load control, in comparison with ETV. A prospective study evaluating approximately 4,000 CHB patients for about 10 years demonstrated the association of viral load levels with risk of the main disease complications (CC, DC and HCC). Our costeffectiveness analysis used data from this study to estimate the incidence of these complications in subjects treated with these drugs, based on the viral load levels in response to therapy.
We observed that ETV promoted an expressive reduction in the number of complications of CHB, both in HBeAgpositive and -negative patients. This reduction led to a decrease in costs of approximately $\mathrm{R} \$ 3$ million, due to expenses for the treatment of these complications. Despite the higher yearly treatment cost, in comparison with LVD, about two million reais more, there was a net reduction of $\mathrm{R} \$ 1$ million, for the total treatment costs for patients with $\mathrm{CHB}$, within a period of 10 years. Under conditions where a drug has a higher cost, but provides a greater benefit, economic analyses are necessary to quantify this benefit for each cost unit, allowing a comparison between treatment alternatives. Frequently, the benefits acquired with the use of a specific therapy can compensate its costs, as our analysis shows.

In addition, ETV resulted in lower ICERs than LVD, for the three endpoints considered: $\mathrm{R} \$-7,938$ and $\mathrm{R} \$-5,420$ per percent of patients reaching an undetectable viral load, $\mathrm{R} \$-2,626$ and $\mathrm{R} \$-1,424$ per life-year gained, and $\mathrm{R} \$-2,930$ and $\mathrm{R} \$-1,590$, per QALY gained, in AgHBe-positive and negative patients.

This analysis was based on two randomized clinical assays, to obtain the percent of patients at different viral load levels, attained with the use of ETV or LVD in a cohort study of around 4,000 patients followed up for approximately 10 years, to determine the incidence of complications. We adapted the cost-effectiveness analysis to the Brazilian situation, using SUS cost data. A recently-published cost-effectiveness study emphasized the importance of economic analysis based on the results of randomized clinical assays [19].

Other important characteristics of this analysis were: the variety of endpoints evaluated for ICER calculation; incorporation, in the analysis, of the risk of disease complications in 10 years; and the use of data from two distinct populations. We examined data for both HBeAg-positive and negative patients, which allowed us to understand how these

Table 9. Incremental Cost-Effectiveness Ratio, in reais, for the three outcomes considered in HBeAg-positive and negative patients in the base case and after 10 years.

\begin{tabular}{|c|c|c|c|c|}
\hline \multirow[t]{2}{*}{ ICER } & \multicolumn{2}{|c|}{1 year } & \multicolumn{2}{|c|}{10 years } \\
\hline & HBeAg + R\$ & HBeAg - R\$ & HBeAg + R\$ & HBeAg-R\$ \\
\hline Cost/patient with undetectable viral load & $-7,938$ & $-5,420$ & $-3,596$ & -250 \\
\hline Cost / LYG & $-2,626$ & $-1,424$ & $-1,662$ & -290 \\
\hline Cost / QALY & $-2,930$ & $-1,590$ & $-1,852$ & -314 \\
\hline
\end{tabular}

LYG - Life-years gained. QALY - Quality Life-years gained. 
different populations react, conferring greater applicability of the results. We also made a comparison with LVD, which is one of the most widely-used drugs in the SUS system to treat $\mathrm{CHB}$, which makes the findings more useful and relevant under a public-health-system perspective.

It is important to use local data, especially efficacy data, to elaborate cost-effectiveness analyses, so that biases related to population differences and disease transmission rates can be minimized.

\section{Conclusion}

ETV, in comparison with LVD, was considered a costsaving drug, promoting lower ICERs for the three endpoints assessed: reduction of viral load to undetectable levels, life-years and quality life-years gained, in the treatment of $\mathrm{CHB}$, both in HBeAg-positive and negative patients. It also reduced total costs due to $\mathrm{CHB}$ treatment, including the cost of complications, within a period of 10 years; this reached $\mathrm{R} \$ 1$ million in the HBeAg-positive patients. Thus, ETV treatment is cost effective, in addition to having superior efficacy.

\section{References}

1. Ministério da Saúde - Programa Nacional de Hepatites Virais. Avaliação da Assistência às Hepatites Virais no Brasil. Brasília;2002:1-61.

2. Ministério da Saúde - Programa Nacional para a Prevenção e o Controle das Hepatites Virais. Disponível em: http:// www.saude.gov.br/sps/areastecnicas/hepatite.htm. 2007.

3. Lok A.S.F., McMahon B.J. Chronic hepatitis B. Hepatology 2001;34:1225-41.

4. Keeffe E.B., Dieterich D.T., Han S.H., et al A treatment algorithm for management of chronic hepatitis b vírus infection in the United States: na update. Clin Gastroenterol Hepatol 2006;4:936-62.

5. Hoofnagle J.H. Hepatitis B - Preventable and now treatable. N Engl J Med 2006;354:1074-6.

6. Dienstag J.L., Lee-Jen Wei, Dong Xu, Bruce Kreter. Cross-study analysis of relative efficacies of oral antiviral therapies for chronic hepatitis B infection in nucleoside-naïve patients. Clin Drug Invest 2007;27:35-49.
7. Chang T.T., et al. A comparison of entecavir and lamivudine for AgHBe-positive chronic hepatitis B. N Engl J Med 2006;354:1001-10.

8. Lai C.L., et al. Entecavir versus lamivudine for patients with HBenegative chronic hepatitis B. N Engl J Med 2006;354:1011-20.

9. Chen C.J., et al. Risk of hepatocellular carcinoma across a biological gradient of serum hepatitis B vírus DNA level. JAMA 2006;295:65-73;

10. Iloeje U.H., et al. Predicting cirrhosis risk base don the level of circulating hepatitis B viral load. Gastroenterology 2006;130:678-86.

11. Chang T.T., Gish R.G., Man R., et al. A comparison of entecavir and lamivudine for AgHBe-positive chronic hepatitis B. N Engl J Med 2006;354:1001-10.

12. Lai C.L., Shouval D., Lok A.S., et al. Entecavir versus lamivudine for patients with AgHBe-negative chronic hepatitis B. N Engl J Med 2006;354:1011-20.

13. Castelo A., Pessoa M.G., Barreto T.C.B.B. Estimativas de custo da hepatite B crônica no sistema único de saúde brasileiro em 2005. Rev Assoc Med Bras 2007;53:486-91.

14. Instituto Brasileiro de Geografia e Estatística (IBGE). Disponível em: www.ibge.gov.br. 2008.

15. Durand-Zaleski I., Zaleski S. DEALE-ing and discounting: a simple way to compute the accrued costs of preventive strategies. Med Decis Making 1994;14:98-03.

16. Bolondi L., Sofia S., Siringo S., et al. Surveillance programme of cirrhotic patients for early diagnosis and treatment of hepatocellular carcinoma: a cost effectiveness analysis. Gut 2001;48:251-9.

17. Fattovich G., Pantalena M., Zagni I., et al. Effect of hepatitis B and $C$ virus infections on the natural history of compensated cirrhosis: a cohort study of 297 patients. Am J Gastroenterol 2002;97:2886-95.

18. Levy A.R., Kowdley K.V., Iloeje U., et al. The impact of chronic hepatitis B on quality of life: a multinational study of utilities from infected and uninfected persons. Value in Health 2007 (December).

19. Veenstra D.L., Sullivan S.D., Clarke L., et al. Cost-effectiveness of entecavir versus lamivudine with adefovir salvage in HBeAg-positive chronic hepatitis B. Pharmacoeconomics 2007;25:963-77.

20. Kanwal F., Farid M., Martin P., et al. Treatment alternatives for hepatitis B cirrhosis: a cost-effectiveness analysis. Am J Gastroenterol 2006;101:2076-89.

21. Yuan Y., Iloeje U.H., Hay J., Saab S. Evaluation of the costeffectiveness of entecavir versus lamivudine in hepatitis BeAgpositive chronic hepatitis B patients. J Manag Care Pharm 2008; $14: 21-33$. 